Steiner (1996): D. T., "For love of a statue: a reading of Plato's Symposium 215AB", Ramus 25, 89-111.

SUÁREZ (1996): E. Suárez de la Torre, "Las Ranas de Aristófanes y la religión de los atenienses", en A. López Eire (ed.) Sociedad, politica y literatura en la Grecia antigua: la comedia griega, Salamanca, 197-217.

SZLEZÁk (1978): Th. A. Szlezák, "Dialogform und Esoterik. Zur Deutung des platonischen Dialogs 'Phaidros'”, $M H 35,18-32$.

SzLeZÁk (1985): Th. A. Szlezák, Platon und die Schriftlichkeit der Philosophie. Interpretationen zu den frühen und mittleren Dialogen, Berlin, de Gruyter.

SZLEZÁK (1999): Th. A. Szlezák, "Gilt Platons Schriftkritik auch für die eigenen Dialoge?: $z u$ einer neuen Deutung von Phaidros 278b8-e4", $Z P h F 53,259-$ 267.

TECUŞAN (1990): M. Tecuşan, "Logos sympotikos: Patterns of the Irrational in the Philosophical Drinking: Plato Outside the Symposium", en MurRay (1990), 238-260.

Usher (2002): M. D. Usher, "Satyr Play in Plato's Symposium, AJPh 123, 205-228.

VetTA (1983), M. Vetta, Poesia e simposio nella Grecia antica. Guida storica e critica, Roma/Bari $\left(1995^{2}\right)$.

VETTA (1992): M. Vetta, "Il simposio: la monodia e il giambo", G. Cambiano, L. Canfora, D. Lanza (direct.), Lo spazio letterario della Grecia antica, I, I, Roma, pp. 177-218.

Villarrubia (2000), A. Villarrubia Medina, "El amor en la poesía lírica de la época arcaica", en M. Brioso Sánchez - A. Villarrubia Medina (eds.), Consideraciones en torno al amor en la literatura de la Grecia antigua, Universidad de Sevilla, Secretariado de Publicaciones, pp. 11-71.
ARNALDO DO ESPÍRITO SANTO

Universidade de Lisboa

\title{
IMAGENS DO AMOR EM SANTO AGOSTINHO
}

Résumé: La multiplicité de nuances qui se cachent sous l'image de l'amour devoile que St. Augustin l'a conçu comme une force universelle qui étend son empire à tout système de valeurs dans lequel s'inscrit l'expérience de I'homme: pondus meum amor meus. C'est auss l'empreinte de cette image qui marque l'essence même de la vie en société. En remplaçant la notion d'amitié comme valeur fondamentale par celle d'amour. St Augustin annonce la fin du monde antique et found la civilisation de la chrétienté médiévale.

A noção de amor em Santo Agostinho envolve matizes complexos e diversificados, pois que nos são dadas ao longo da sua obra definições que relevam do plano ontológico, outras que se inclinam para o domínio dos afectos e das emoções, outras que se situam no campo da ética religiosa, outras ainda que entram no âmbito da gnoseologia.

Numa primeira abordagem, o amor é tomado como uma entidade de carácter geral que se define no discurso linguístico pelos substantivos, adjectivos ou expressões que o determinam. Há um amor rectus e um amor pravus; um amor Dei e um amor sui; um amor carnis e um amor spiritualis; um amor rerum amandarum, que coincide com o conceito de charitas, um amor do que é eterno, e um amor que não passa de uma cupiditas rerum transeuntium; há um amor excellentiae que se confunde com a superbia, um amor laudis que é o mesmo que vanglória; um amor pecuniae que, por outros termos, é simplesmente a avareza; há um amor saeculi e um amor Dei, nas suas duas vertentes de amor hominum erga Deum e de amor Dei erga homines; há o amor proximi; há o amor esuriens do início da viagem mística para o sumo bem, e o amor fruens, o amor que repousa no objecto amado; há o amor indissociável do temor; não há amor sem dor; não há amor sem Fé e 
sem Esperança; todo o amor é uma força extraordinária bidireccional que aut ascendit aut descendit, e que torna fáceis as coisas difíceis; há o amor temperantiae, o amor fortitudinis, o amor iustitiae, o amor prudentiae; o amor é a perfeição do homem e a totalidade da sua vida; o amor é Cupido voando e sagitando, porque, irracional e instável, fere o coração dos infelizes; mas também é figurado como uma seta do mesmo Cupido, a qual, simbolizando a palavra de Deus, atinge a alma para a despertar para si; o objecto do amor é o bem, porque ninguém ama o mal enquanto mal; o amor é invisível; o amor é o próprio Deus, no seio da Trindade; há dois amores que definem duas cidades; não há amor sem conhecimento verdadeiro, pois ninguém ama o que não conhece; amar é conhecer e possuir; o amor é uma corrida como a do atleta no estádio, cujo prémio é o próprio Deus; o amor é forte como a morte; o destino final de todo o ser é o amor, princípio e fim de todas as coisas, porque ele é a vita vitarum. Enfim, o amor é uma espécie de densidade do ser: pondus meum amor meus.

Todos estes matizes são de Agostinho. E outros mais, muitos mais, ficaram de fora desta lista. Não há pormenor nem aspecto da consciência humana que escape a essa torrente avassaladora que é o amor.

Existem estudos profundíssimos, já clássicos, sobre o amor em Agostinho, quer do ponto de vista teológico e filosófico, quer na perspectiva da psicologia, com análises penetrantes e sábias no domínio da fenomenologia da consciência. Não é em trinta minutos que vou falar sequer de algumas das conclusões desses estudos. Além do mais, sobre o tema desta palestra poderiam escrever-se alguns volumes e bem grossos. Falar sobre elas em tempo tão reduzido não permitiria ir além de uma amável superficialidade, bem apoiada em autoridades, correndo o risco de repetir banalidades envoltas em frases bombásticas.

A minha decisão, ao aceitar o convite da Doutora Maria do Céu Fialho que agradeço pela confiança sem limites que em mim depositou, a minha decisão, digo, foi falar do amor em Agostinho, sem pretensões, de tal modo que até as palavras fossem de Agostinho. Há trechos maravilhosos em que 0 lirismo do estilo e a vivacidade da emoção correriam o risco de se desvanecerem se tentasse dissecá-los numa análise esmiuçada de ideias e conceitos. Tanto quanto possível, deixarei falar os textos recorrendo profusamente à citação. Procurarei, além disso, dar relevo a aspectos menos glosados pelos especialistas de Agostinho.

A enumeração, com que iniciei esta palestra, sobre os vários matizes implícitos na noção de amor em Agostinho, mostra claramente que o amor é concebido como uma força que estende o seu império a todo o sistema de valores em que assenta a vida do ser humano, na sua relação, transcendental e horizontal, consigo mesmo e com o outro, com o indivíduo e com a sociedade. Não será exagerado dizer que Agostinho, ao empregar 6864 vezes as palavras amor, charitas, dilectio, contra 227 ocorrências de amicitia, numa proporção de 100 para 3, tinha plena consciência de que estava a mexer nos fundamentos da cultura e da sociedade antiga, já em vias de cristianização acelerada. Uma comparação feita com o uso do mesmo vocabulário em Cícero e Séneca só vem confirmar esta opinião. De facto, nem em Cícero nem em Séneca aparece a palavra dilectio, e caritas apenas umas 40 vezes em Cícero e 9 em Séneca. Mas o que mais interessa é que em Cícero é significativamente menor o número de ocorrências de amor do que o de amicitia (356 contra 493, numa proporção de 72 para 100).

Desculpem-me esta estatística, aparentemente despropositada ao falar de amor, mas a verdade é que as palavras, mudadas, são aqui o reflexo das coisas e de outras mudanças. Numa sociedade fundada no relacionamento horizontal entre os individuos, regido por códigos morais exclusivamente humanos, sem um apelo à divindade, ética e ontologicamente fundamentado, a relação entre os indivíduos assenta na amizade'. E é precisamente esta palavra que quase desaparece para dar lugar à predominância absoluta de amor. O que Agostinho faz realmente é situar-se no quadro dos valores que regem os impulsos afectivos do ser humano, como ser individual e social, para lhe conferir outro tipo de fundamentações que a não muito longo prazo vão alterar completamente a mentalidade dos indivíduos: a principal dessas fundamentações consistiu em acentuar o sentido da verticalidade no relacionamento horizontal.

Desta forma, a sociedade antiga, fortemente alicerçada no valor da amizade, cedeu o lugar a uma forma de ver o mundo e a vida sob outro prisma, privilegiando outros nexos dos homens entre si, do homem consigo e do homem com a divindade.

Não admira, pois, que Agostinho implique na concepção de amor uma crítica tenaz e implacável a um dos mais nobres valores do mundo antigo, qual era o amor laudis ou amor gloriae, cultivado por heróis, incentivado por poetas e pedagogos, como um dos motores mais eficazes dos grandes feitos que engrandeciam a pátria que tais heróis gerava. Todos reconhecemos esse espírito em Homero, Píndaro, Virgílio, Horácio, Tito Lívio, Salústio, etc. Agostinho, porém, tem outra concepção sobre as motivações do agir humano. Mesmo na justa defesa da pátria, não deve ser a ambição de adquirir glória

'Há também a pietas para com os deuses, para com os pais e a familia, e para com a pátria. Mas essa é outra questão e de outro domínio. 
humana o móbil da acção, mas, antes um objectivo superior como a necessidade de garantir a liberdade e a salvação comum. Saliento três aspectos na argumentação usada por Santo Agostinho.

O primeiro é que a crítica ao amor humanae laudis é acentuada com expressões crescentemente negativas: cupiditas gloriae, cupiditas laudis humanae, aviditas laudis humanae. Numa expressão mais completa, o amor laudis et affectatio dominandi, que os animais não possuem, não dignifica o ser humano em relação aos irracionais, pois que se trata de um desejo (appetitus) irracional (rationi non subditus) que só pode levar à infelicidade. E Agostinho conclui assim o seu pensamento: «Non enim ordo rectus, aut ordo appellandus est omnino, ubi deterioribus meliora subjiciunturs ${ }^{2}$. Este princípio, se aplicado às sociedades humanas, constitui uma inversão dos valores da tradição ética do mundo clássico.

O segundo aspecto que convém salientar é que a argumentação de Agostinho se apoia em factos narrados por Salústio e celebrados por Vergílio, como que na intenção de atacar o problema na fonte, sabendo muito bem que ambos os textos não eram apenas um repositório dos valores consagrados, mas o meio mais eficaz de os transmitir de geração em geração. A primeira crítica de Agostinho incide sobre a história de Júnio Bruto, um dos dois primeiros cônsules de Roma, que esmagou uma tentativa de fazer voltar Tarquínio, o Soberbo, com a morte dos implicados no golpe, entre os quais se encontravam os filhos e a mulher de Bruto. Este episódio da história de Roma é apresentado e criticado por três vezes. E, embora Agostinho retome em pormenor a narrativa de Salústio, resume ou cita numa dessas vezes os versos 820-823 do livro VI da Eneida:

«Natosque pater nova bella moventes

Ad poenam pulchra pro libertate vocabit,

Infelix, utcumque ferent ea facta minores.»

Aí interrompe a citação para comentar que quem mata os filhos não pode ser feliz, e que o apelo ao amor da pátria não passa de uma vã consolação para essa infelicidade, argumentando a sua demonstração com o verso seguinte:

«Vincit amor patriae laudumque immensa cupido.»

De Libero arbitrio, PL 32, 1231: «Não se deve designar por ordem recta, nem mesmo por ordem, quando as coisas melhores se subordinam às piores».
Mas, num outro passo, as palavras do poeta são desvalorizadas por Agostinho que classifica a glória historicamente alcançada por Júnio Bruto como «detestanda iniquitas et nihilo utilis reipublicae». A isto chama-se desmontar pela base todo o aparelho da superstrutura dos valores essenciais de uma civilização que não está fundamentada num «ordo rectus», numa hierarquia racional de princípios.

O terceiro aspecto a considerar é que, das 78 vezes em que Agostinho apela para Vergílio, $50 \%$ delas surgem na cidade de Deus. É este um facto significativo, sendo nesta obra que Agostinho empreende a crítica sistemática e fundamentada da cidade pagã ainda muito vigorosa nas tradições e nos valores que a fundamentavam. Seria interessante fazer a análise de todas as citaç̃es desse Vergilio, «hunc Virgilium, [...] quem propterea parvuli legunt, ut videlicet poeta magnus omniumque praeclarissimus atque optimus teneris ebibitus animis non facile oblivione possit abolerim. ${ }^{3}$ Mas seria muito longo fazê-lo e afastar-nos-ia do nosso propósito. Registemos, no entanto que a recomendação de Agostinho é que, se não se conseguir extirpar do coração a cupiditas gloriae, pelo menos se the anteponha a dilectio justitiae e o amor veritatis.

Por conseguinte, quando escreve «Fecerunt itaque civitates duas amores duo» ${ }^{4}$ ou «Duas istas civitates faciunt duo amores» ${ }^{5}$, Agostinho não está a usar apenas uma alegoria sem relação concreta com a realidade. Está, pelo contrário, a opor uma sociedade, a velha sociedade com todos os seus amores ou valores, à nova sociedade antevista de longe e cimentada no amor Dei: «Jerusalem facit amor Dei; Babyloniam facit amor saeculi» ${ }^{6}$. Cada um tem que analisar com atenção aquilo que ama, para ver de que cidade é cidadão. E, se vir pela análise da qualidade do seu amor que é cidadão dessa Babilónia que é o mundo presente a Agostinho, com todos os seus valores intactos, então «exstirpet cupiditatem, plantet charitatem» ${ }^{7}$, isto é, substitua a cupiditas, «quia nihil aliud est cupiditas nisi amor rerum transeuntium».

${ }^{3}$ De Civit. Dei, PL 41, 16: «Este Vergílio [...] que as crianças lêem precisamente para que o grande poeta, o mais ilustre e o melhor de todos, absorvido pelo seu espírito ainda tenro, não possa facilmente ser delido pelo esquecimento.»

${ }^{4}$ De Civit. Dei, PL 41, 436: «Portanto, dois amores construíram duas cidades». cidades».

${ }^{6}$ Ennarrat. in Psalmos, PL 36, 773: «O amor de Deus constrói Jerusalém; o amor do mundo constrỏi Babilóniay.

${ }^{7}$ Ennarrat. in Psalmos, PL 36, 773: «arranque a cupidez, plante a caridade».

${ }^{8}$ De Divers. Quaestionibus, $P L 40,22$ : «porque a cupidez não é senão o amor das coisas efémeras». 
Com efeito, «si amandus est amor, non utique omnis amandus est». ${ }^{9}$ Há um amor torpe, feio, que altera a boa ordem, a harmonia do ser, em razão da qual um ser de nível superior não deve deixar-se dominar por outro de nível inferior. E este amor turpis «quo animus se ipso inferiora sectatur» ${ }^{10} \mathrm{com}$ mais propriedade se deveria chamar cupiditas.

Neste ponto, o discurso muda de registo ou passa a funcionar em dois registos justapostos, ainda que complementares, deixando de estar objectivado sobre um sistema de valores em concreto, como o que se vira na história de Roma, para se concentrar numa oposição abstracta entre duas forças dentro do homem, coexistentes no mesmo momento e na mesma sociedade. E permitam-me que cite mais uma vez a cidade de Deus: «quapropter quod nunc in civitate Dei, et civitati Dei in hoc saeculo peregrinanti maxime commendatur humilitas, et in ejus Rege, qui est Christus, maxime praedica-tur; contrariumque huic virtuti elationis vitium, in ejus adversario, qui est diabolus, maxime dominari, sacris Litteris edocetur: profecto ista est magna differentia, qua civitas, unde loquimur, utraque discernitur; una scilicet societas piorum hominum, altera impiorum, singula quaeque cum Angelis ad se pertinentibus, in quibus praecessit hac amor Dei, hac amor sui.» ${ }^{11}$

Nos trechos atrás citados, dizia Agostinho que «duas civitates faciunt duo amores.» Mas agora este dualismo amplifica-se, instaurando uma oposição de carácter mais universal entre dois amores antagónicos: "Duo sunt amores, mundi et Dei» ${ }^{12}$. E tão antagónicos que «si mundi amor habitet, non est qua intret amor Dei: recedat amor mundi et habitet Dei; melior accipiat locum. Amabas mundum, noli amare mundum: cum exhauseris cor tuum

${ }^{9}$ De Divers. Quaestionibus, PL 40,23: «se o amor deve ser amado, a verdade é que nem todo o amor deve ser amadoy.

${ }^{10}$ De Divers. Quaestionibus, PL 40, 23: «pelo qual [o homem] segue coisas inferiores a si próprion.

"De Civit. Dei, PL 41, 420. A Cidade de Deus, Tradução, prefácio, nota biográfica e transcrições de J. Dias Pereira, Lisboa, Fundação Calouste Gulbenkian, 1993, vol. II, p.1279: «É por isso que agora, na cidade de Deus e à cidade de Deus, a peregrinar neste século, muito se recomenda a humildade, altamente exaltada no seu rei que é Cristo. Nas Sagradas Escrituras ensina-se que o vício da soberba, contrário a essa virtude, domina sobretudo no seu adversário que é o diabo. Sem dúvida que é grande a diferença que opõe as duas cidades: uma, a sociedade dos homens piedosos, a outra, a dos ímpios, cada uma com os seus anjos próprios em que prevaleceu o amor de Deus ou o amor de si mesmo.»

${ }^{12}$ In Epist. Joannis ad Parthos tract. X, PL 35, 1993: «Há dois amores: o do mundo e de Deus». amore terreno, hauries amorem divinum; et incipit habitare jam charitas, de qua nihil mali potest procedere $\rangle^{13}$. Esta sucessão de antíteses de uma grande simplicidade, mas ao mesmo tempo de uma elegância sugestiva, é completada com a alegoria recorrente em Agostinho da actividade do agricultor, que ora limpa o silvedo, ora semeia e planta o terreno já limpo: «Quasi agrum invenit corda hominum: sed quomodo invenit? Si silvam invenit, exstirpat; si agrum purgatum invenit, plantat. Plantare ibi vult arborem, charitatem. Et quam silvam vult exstirpare? Amorem mundi. $\left.{ }^{14}\right\rangle$

Em toda esta oposição - «amor Dei, amor proximi, charitas dicitur: amor mundi, amor hujus saeculi cupiditas dicitur» ${ }^{15}$ - não saímos de um registo em que predominam os aspectos etico-religiosos, com alguns afloramentos pela mística. Agostinho, um dos fundadores ou fundamentadores da Idade Média, como foi chamado, teve uma enorme influência em todo o desenvolvimento de uma atitude espiritual e intelectual que passa pelo contemptus mundi, derivada da oposição amor Dei / amor mundi, e que conduziu a uma das mais fecundas formulações da teologia da perfeição e do amor de Deus no séc. XII. Refiro-me à Escola de S. Victor, e, particularmente, a Ricardo de S. Victor, um dos teólogos da experiência de Deus. Tal como Agostinho, Ricardo de S. Victor acentua o papel da inteligência humana num percurso que conduz à compreensão de Deus. Se é impossível, por via da especulação natural demonstrar seja o que o que for a respeito da sua essência, é, no entanto, possivel explicitar o conteúdo da revelação cristã e torná-la acessível à razão. Com este excurso pretendo exemplificar que em todo o desenvolvimento posterior das linhas de pensamento augustinianas o amor foi o ponto fulcral em que veio assentar uma visão teocêntrica do universo desenvolvida pela reflexão da teologia ocidental. Se da Idade Média passarmos ao Renascimento, encontraremos no humanismo cristão a mesma presença de uma theologia vivificans fundada na profundidade do mistério do amor de Deus entre os homens. No centro dessa teologia, está, tal como em

${ }^{13}$ In Epist. Joannis ad Parthos tract. X, PL 35, 1993: «Se habitar o amor do mundo, não há por onde entre o amor de Deus: váase embora o amor do mundo e habite o amor de Deus. Que o melhor tome o lugar. Amavas o mundo, não ames o mundo. Quando esvaziares o teu coração do amor terreno, absorverás o amor divino; e começará logo a habitar a caridade, da qual nada de mau pode derivar».

${ }^{14}$ In Epist. Joannis ad Parthos tract. X, PL 35, 1993: «Encontra o coração do homem como si fosse um campo: mas como o encontra? Se encontra um matagal, arranca. Se encontra um campo limpo, planta. Quer aí plantar uma árvore, a caridade. E que matagal quer arrancar? O amor do mundo.»

${ }^{15}$ Ennarrat. in Psalmos, PL 36, 260: «o amor de Deus e o do próximo chamam-se caridade: 0 amor do mundo, o amor deste mundo chama-se cupidez.» 
Agostinho, o mistério da Trindade e da essencialidade do amor em toda a criatura, como uma espécie de força seminal que a move para um centro de gravidade que é o próprio Deus. Não se trata de uma imagem abstracta para dar cor a esse impulso vital que parece mover todas as coisas. Mais do que isso, trata-se da natureza intrínseca da criatura, não enquanto emanação de Deus, mas enquanto não-ser que é chamado à existência por uma vontade criadora, em perfeita alteridade e em perfeita gratuitidade de um acto de amor que faz com que o ser seja e permaneça. Assim o diz Santo Agostinho: «Duo quippe sunt propter quae amat Deus creaturam suam; ut sit, et ut maneat. Ut esset ergo quod maneret, Spiritus Dei superferebatur super aquam; ut autem maneret, Vidit Deus quia bonum est. Et quod de luce dictum est, hoc de omnibus. Manent enim quaedam supergressa omnem temporalem volubilitatem in amplissima sanctitate sub Deo; quaedam vero secundum sui temporis modos, dum per decessionem successionemque rerum saeculorum pulchritudo contexitur.s) ${ }^{16}$

O que subjaz a estas palavras é uma visão grandiosa de um Ser Supremo, que é Supremo Amor, Beleza Suprema e Sumo Bem, que paira sobre o universo como sobre as águas no acto primigénio da criação. E vê que é bom tudo o que cria. E faz com que permaneça. Umas coisas permanecem tendo ultrapassado toda a contingência da temporalidade, na visão da permanência sob a amplíssima santidade de Deus. Outras vivem sujeitas ao tempo constituindo, pela sucessão dos tempos - morrendo e nascendo, nascendo e morrendo - a imensa beleza dos séculos. É de facto grandiosa esta imagem.

Agostinho refere-se, neste contexto, a uma scintilla gratuiti amoris Dei, ou, em expressão reduzida, scintilla boni amoris. É de notar que este termo scintilla vem de Lucrécio e que é utilizado para explicar o que são os semina rerum que constituem a parte activa da matéria. Essa parte activa em Agostinho é a scintilla gratuiti amoris. E por isso exorta: «Si ergo sermo meus invenit in cordibus vestris aliquam scintillam gratuiti amoris Dei, ipsam nutrite: ... dilectione justitiae, ... amicitia fideli. Hanc scintillam boni amoris

${ }^{16}$ De Gen. ad litteram, PL 34, 251: «São de facto dois os motivos por que Deus ama a sua criatura: para que seja e para que permaneça. Para que fosse coisa que permanecesse, o Espirito de Deus pairava sobre a água. Para que permanecesse, Deus viu que é bom. E o que foi dito da luz, foi dito de todas as coisas. Permanecem, com efeito, certas coisas que vencem toda a volubilidade temporal na amplissima santidade sob Deus; outras coisas permanecem segundo a medida da sua duração, enquanto pelo desaparecer e suceder das coisas se entretece a beleza dos séculos.» flate in vobis, nutrite in vobis: ipsa cum creverit, et flammam dignissimam et amplissimam fecerit, omnium cupiditatum carnalium fena consumit.. ${ }^{17}$

É desnecessário insistir em que as imagens e as palavras de Agostinho têm a sua tradição na literatura clássica pagã. Mas o que as distingue é que falam de outra realidade sem que, no entanto, deixem de evocar os contextos ideológicos em que nasceram. Há neste processo como que uma intenção determinada de substituir as categorias desse mundo pagão pelas categorias da nova doutrina. A visão do mundo muda radicalmente de figura quando se diz que «in baptizatis parvulis, quamvis id nesciant, habitare Spiritum Sanctum ${ }^{18}{ }^{18}$, o qual se identifica com o amor vivo que faz com que o universo seja e permaneça. A criança ignora a sua inteligência, que vai despertando com a idade: «Sic enim eum nesciunt quamvis sit in eis, quemadmodum nesciunt et mentem suam; cujus in eis ratio, qua uti nondum possunt, velut quaedam scintilla sopita est, excitanda aetatis accessu. ${ }^{19}$ Mas o apelo a essa força, de ordem profundamente espiritual, faz a diferença em relação aos pressupostos da mundividência pagã, apesar das sublimes elevações da filosofia platónica e estóica.

Agostinho não perde uma oportunidade para reavaliar os pressupostos da mentalidade antiga, sobretudo uma espécie de materialismo on imanentismo ético, que centra a procura da felicidade na fruição dos bens materiais. Mas o que acontece, diz Agostinho, é que, amando os bens perecíveis e esperando deles a felicidade, acabam por descer da sua condição de seres espirituais e livres, tornando-se escravos de seres que thes são inferiores. Esta crítica vem assim formulada no De Vera religione. Agostinho, depois de atacar, o «deterior et inferior cultus simulacrorum, quo phantasmata sua colunt $\rangle^{20}$, volta-se para uma tríplice cupiditas ou amor rerum transeuntium: «Serviunt enim cupiditati triplici, vel voluptatis, vel excellentiae,

${ }^{17}$ Sermones de Scripturis, PL 38, 965: «Se, pois, o meu sermão encontrou nos vossos corações alguma centelha do gratuito amor de Deus, alimentai-a: ... com o amor da justiça, ... com a amizade na fé. Soprai em vós a essa centelha do bom amor, alimentai-a em vós. Quando ela crescer e fizer uma chama bem grande e ampla, consumirá a palha de todas as paixões carnais».

${ }^{18}$ Epistolae, $P L$ 33, 841: «nas crianças baptizadas, embora o não saibam, habita o Espirito Santo..

${ }^{19}$ Epistolae, PL 33, 841 : «Com efeito não o conhecem, embora esteja neles, da mesma maneira que desconhecem a sua mente; neles está adormecida a razão, de que ainda não podem usar, como uma espécie de centelha, a ser espevitada com o desenvolvimento da idade.

${ }^{20}$ De Vera religione, PL 34, 153: «o pior e inferior culto dos ídolos, com que adoram os seus fantasmas.» 
vel spectaculi» ${ }^{21}$. E conclui: «Ita nescientes diligunt temporalia, ut inde beatitudinem exspectent. His autem rebus quibus quisque beatus vult effici, serviat necesse est, velit nolit. $\rangle^{22}$

O que Agostinho proclama é, portanto, a libertação das dependências do paganismo. É preciso mudar tudo. E ele sabe o que está a fazer: que a médio ou a longo prazo o seu pensamento, expresso num discurso renovado, com uma retórica límpida que sabe utilizar todos os recursos da exposição clara e da persuasão, irá atrair multidões que se hão-de alimentar das suas ideias e fazer delas um programa de vida, que as hão-de copiar e proclamar do alto do púlpito, modelando pouco a pouco uma sociedade diferente, convidada continuamente a tomar consciência, cada vez mais profundamente assumida, dessa scintilla amoris que é o princípio e o fim de todas as coisas.

As interrogações do Homem continuam a ser as mesmas: mas as soluções apresentadas são diferentes. Agostinho reconhece e declara que para Platão Deus é a origem de todos os seres, da inteligência e do amor com que se vive em bem e felicidade («bene beateque»). Mas a insistência em que se deve usar apenas das coisas temporais, sem fruir delas, para que possamos fruir dos bens eternos, isso é uma resposta que deriva de outros pressupostos. Se a nossa natureza nos pertencesse, e continuo a glosar Agostinho, geraríamos o saber e o amor para atingir a perfeita felicidade, e não precisaríamos de mais nada. Mas porque a nossa natureza tem origem em Deus, dele temos necessidade para que o objecto do nosso saber seja a verdade e a nossa vida a felicidade. ${ }^{23}$

Nesta perspectiva teocêntrica, o amor não é mais que uma força que nos atrai para o lugar a que pertencemos. Cada ser tem a sua densidade específica. Quando se deita azeite e água num recipiente, o azeite apressa-se a vir ao de cima, ocupando cada líquido o lugar que pertence à sua natureza: «ponderibus suis aguntur, loca sua petunt.) ${ }^{24}$ Todos vemos que na Natureza as coisas que têm uma estrutura de fraca coesão dos seus elementos são instáveis. E com esta imagem da gravidade e da densidade específica dos

${ }^{21}$ De Vera religione, PL 34, 153: «na verdade, servem a uma tríplice cupidez, a da volúpia, a da excelência, a do espectáculo.»

22 De Vera religione, $P L$ 34, 153: «Assim, por ignorância, amam as coisas temporais, esperando delas a felicidade. Queira ou não queira, é inevitável que cada um seja escravo daquilo com que pretende ser feliz.»

${ }^{23}$ De Civit Dei, PL 41, 338: «ut vera sapiamus [...] ut beati simus».

${ }^{24}$ Confess., PL 32, 848: «Levados pelos seus pesos, procuram os lugares que lhes são próprios.) corpos Agostinho dá evidência ao seu pensamento: «O nosso repouso é o nosso lugar. Para lá nos eleva o teu amor, e o teu espírito de bondade arranca a nossa baixeza das portas da morte. Na tua boa vontade está a nossa paz. O corpo, com o seu peso, tende para o lugar que the é próprio O peso não tende apenas para baixo, mas para o lugar que the é próprio O fogo tende para cima, a pedra para baixo. Levados pelos seus pesos, procuram os lugares que lhes são próprios. O azeite deitado na água sobe ao de cima da água, a água deitada no azeite desce para debaixo do azeite: levados pelos seus pesos, procuram os lugares que lhes são próprios. As coisas menos ordenadas não estão em repouso: ordenam-se e ficam em repouso. O meu peso é o meu amor; sou levado por ele para onde quer que seja levado. ${ }^{25}$

Este passo é de uma grande beleza e de uma efusão lírica contida, que explode em frases curtas justapostas, como que em vagas sucessivas num vaivém incessante, acentuado pelo repetição do dímetro sentencioso «Pondus meum, amor meus». O fogo do amor incendeia-nos. Somos levados para as alturas. O fogo do amor torna-nos mais leves e subimos. Se fôssemos animais irracionais, bastava que amássemos a vida carnal, e aí estaria todo o nosso bem. Se fôssemos árvores, sem termos nenhum impulso para o amor, bastar-nos-ia essa espécie de desejo ínsito na matéria vegetal, desejo ou determinação genética, que nos levaria a constituir a felicidade na fertilidade dos frutos produzidos. Se fôssemos pedras, e continuo a parafrasear Agostinho, ou vento, ou onda, ou chama, sem sensibilidade e sem vida, não nos faltaria uma espécie de tendência ou força de gravidade para ocupar um lugar na ordem do universo. Enfim, todos os «amores corporum» os arrastam para baixo pela densidade do seu peso, ou para cima pela leveza da sua imaterialidade. Deste modo, em conclusão implícita, «Assim como um corpo

${ }^{25}$ Santo Agostinho, Confissões, Tradução e notas de Arnaldo do Espírito Santo, João Beato e Maria Cristina de Castro-Maia de Sousa Pimentel, Centro de Literatura e Cultura Portuguesa e Brasileira, Imprensa Nacional Casa da Moeda, Lisboa, s.d. [2000], livro XIII, IX, 10. Confess., PL, 32, 848: «Requies nostra, locus noster. Amor illuc attollit nos, et Spiritus tuus bonus exaltat humilitatem nostram de portis mortis (Psal. IX, 15). In bona voluntate pax nobis est (Luc. II, 14) Corpus pondere suo nititur ad locum suum. Pondus non ad ima tantum est, sed ad locum suum. Ignis sursum tendit, deorsum lapis. Ponderibus suis aguntur, loca sua petunt. Oleum infra aquam fusum, supra aquam attollitur; aqua supra oleum fusa, infra oleum demergitur; ponderibus suis aguntur, loca sua petunt. Minus ordinata, inquieta sunt; ordinantur et quiescunt. Pondus meum amor meus; eo feror quocumque feror.» 
é arrastado pelo seu peso, assim o espírito pelo seu amor» ${ }^{26}$ Este passo condensa toda a experiência de Agostinho, já lapidarmente expressa logo no princípio das Confissões e que ele, de certo modo, impôs à posteridade como corolário da condição humana: «tu nos fizeste para ti, e o nosso coração está inquieto enquanto não repousar em ti.. ${ }^{27}$

Deste modo, porque somos criaturas espirituais, modeladas à imagem de Deus, verdadeira eternidade, eterna verdade, eterna e verdadeira caridade, eterna, verdadeira e amável Trindade, não devemos deixar-nos arrastar por aquilo que é inferior a nós. Porque todas elas não existiam, ou não teriam ser, se não tivessem sido criadas por aquele que é o Ser Supremo, a Suprema Sabedoria e o Supremo e Sumo Bem. O nosso lugar de repouso, de acordo com a ordem do ser, é aquele em que «esse nostrum non habebit mortem», «nosse nostrum non habebit errorem», "amare nostrum non habebit offensionem». ${ }^{28}$

Entretanto, a realidade mostra que a vontade é atraída em sentidos opostos, sujeita como está a forças contrárias: o amor saeculi e o amor mundi. E destas duas forças, aquela que. vencer a luta «illuc amantem tamquam pondere trahit» ${ }^{29}$. Por sua origem e natureza, o peso da alma impele-a para as alturas. Mas há o rerum terrenarum amor que, qual viscum animae, impede o movimento ascensional: «Quod amas in terra, impedimentum est: viscum est pennarum spiritualium, hoc est virtutum, quibus volatur ad Deum. Capi non vis, et viscum amas? ${ }^{30}$ Esta imagem do visco anda associada à imagem da alma como um ser alado, cujas penas, quando libertas, a elevam para as alturas. $\mathrm{E}$ assim como o amor imundo exerce uma força de atracção para o que é terreno e efémero, precipitando-a no abismo, assim também o amor santo a eleva nas asas do desejo para aquilo que é eterno. Não é da natureza do amor ser inactivo. Se é amor terá que amar: «Necesse est ducat». A nossa obrigação é ver para onde nos conduz: "Habet tamen amor vim suam».

${ }^{26}$ De Civit. Dei, PL 41, 341: «Ita enim corpus pondere, sicut animus amore fertur».

${ }^{27}$ Santo Agostinho, Confissões, livro I, 1, 1. PL, 32, 659: «quia fecisti nos ad te et inquietum est cor nostrum, donec requiescat in te.3)

${ }^{28}$ De Civit. Dei, PL 41, 341: «O nosso ser não terá morte», «o nosso conhecer não terá erro», «o nosso amar não terá obstáculo».

${ }^{29}$ Sermones de diversis, PL 39, 1512: «para aí arrasta o amante como que com um peso».

${ }^{30}$ Semones de Sanctis, PL 38, 1: «O que amas na terra é um impedimento: é visco das asas espirituais, isto é das virtudes, com que se voa para Deus. Não queres ser apanhado, e amas o visco?»
A alma que está enlaçada pelo amor terreno «tem visco nas penas, não pode voar». ${ }^{31} \mathrm{E}$ esta imagem termina com um conselho: «O meu conselho não é que não ameis coisa alguma, mas que não ameis o mundo, para amardes livremente aquele que fez o mundo.» ${ }^{32}$ Há um «amor tartareus» ${ }^{33}$ que com o seu visco arrasta para o abismo. Mas há também um amor que tem "penas com que eleva para o céu». ${ }^{34}$

\footnotetext{
${ }^{31}$ Ennarat. in Psalmos, PL 37, 1618: «quasi viscum habet in pennis, volare non potest»)

${ }^{32}$ Ennarat. in Psalmos, PL 37, 1618: «Non ergo monemus ut nihil ametis; sed monemus ne mundum ametis, ut eum qui fecit mundum, libere ametis.»

${ }^{33}$ Ennarat. in Psalmos, PL 37, 1815

${ }^{34}$ Ennarat. in Psalmos, PL 37,1815
} 